\title{
CHERNOBYL NUCLEAR ACCIDENT
}

T.V. Kozlenko - Sumy State University, group M-03 V. S.Kurochkina - E L Adviser

Chernobyl break down is an ecological disaster that was caused by the destruction of the fourth unit of Chernobyl nuclear power plant. It happened in Ukraine on 26 April 1986. The disaster is the largest in the history of nuclear power.

After the accident a radioactive cloud appeared over the European part of the USSR, the greater part of Europe, the eastern part of the United States. Approximately $60 \%$ of nuclear fallout was deposited on the territory of Belarus. About 200,000 people were evacuated from the areas of contamination. First, the leadership of the USSR tried to conceal the scale of the tragedy, but after the reports from Sweden and the assessment of contamination, evacuation of about 130,000 residents of Kyiv region from the contaminated areas was organized. There was created a $30-\mathrm{km}$ exclusion zone around Chernobyl.

The accident resulted in emission of radioactive substances, including uranium, plutonium, iodine-131 (half-life of 8 days), cesium-134 (half-lifeof 2 years), cesium-137 (half-lifeof 33 years), strontium-90 ( half-life of 28 years).

In the first weeks after the accident, radioactive iodine and tellurium were the most dangerous substances to people.

After the Chernobyl catastrophe, 116,000 people from Pripyat, Chernobyl, over 70 settlements were evacuated from the 30-kilometer zone. Altogether, 600000 people, including liquidators of the disaster, have been affected by the radiation.

Such breakdowns as at Chernobyl or Japan's Fukushima nuclear plants force humanity to be alert and encourage scientists to invent the alternative energy sources. 